\title{
A STUDY OF CHANGES IN CARDIAC ECHOCARDIOGRAPHY IN CIRRHOSIS OF LIVER
}

\author{
Boddu Jyotirmayi ${ }^{1}$, V. C. Srinivas Reddy ${ }^{2}$
}

${ }^{1}$ Assistant Professor, Department of General Medicine, Andhra Medical College, Visakhapatnam, Andhra Pradesh. ${ }_{2}^{2}$ Assistant Professor, Department of General Medicine, Andhra Medical College, Visakhapatnam, Andhra Pradesh.

ABSTRACT
BACKGROUND
Cirrhosis of liver with portal hypertension results in hyperdynamic circulatory state. This is associated with a variety of
cardiovascular alterations. In addition, the heart in patients with cirrhosis presents with structural and functional abnormalities that
have been termed cirrhotic cardiomyopathy.
The aim of this study is to assess the changes in cardiac echocardiography in patients with cirrhosis of liver.

\section{MATERIALS AND METHODS}

We have included 50 patients of cirrhosis of liver as the study group and another 50 persons as the control group. All the participants were subjected to M-mode and two-dimensional (2D) echocardiography. The results were compared.

\section{RESULTS}

54 percent of cases had ascites. The mean Right Ventricular End Diastolic (RVEDD) and end systolic (RVESD) diameters were significantly higher in cirrhotic patients compared to healthy controls ( $p=0.000$ and 0.000 , respectively). RVEDD was significantly larger in cirrhotics with ascites than those without ascites $(p=0.00)$. The $E / A$ was significantly lower in cirrhotics with ascites compared to those without ascites $(\mathrm{p}=0.00)$. The ejection fraction and cardiac output were comparable between the alcoholics and non-alcoholics.

\section{CONCLUSION}

Cirrhotic patients in our study showed right ventricular enlargement and diastolic dysfunction. Patients with ascites were more likely to have diastolic dysfunction.

\section{KEYWORDS}

Cirrhosis of Liver, Cardiomyopathy.

HOW TO CITE THIS ARTICLE: Jyotirmayi B, Reddy VCS. A study of changes in cardiac echocardiography in cirrhosis of liver. J. Evolution Med. Dent. Sci. 2016;5(95):7019-7021, DOI: 10.14260/Jemds/2016/1587

\section{BACKGROUND}

Hyperdynamic circulatory state is a well-recognised haemodynamic change found in patients with cirrhosis and portal hypertension. This is caused by increase in vasodilator factors and decrease in vascular reactivity to vasoconstrictors. ${ }^{[1]}$

"Cirrhotic cardiomyopathy" denotes a condition of impaired contractile responsiveness to stress, diastolic dysfunction and electrophysiological abnormalities in the absence of known cardiac disease in the patients of cirrhosis of liver.[2],[3] Its diagnosis is based on the demonstration of cardiac abnormalities in patients with cirrhosis of the liver in the absence of other clinically significant cardiopulmonary disease. $[4,5]$

Moreover, both ventricular systolic and diastolic function are impaired in cirrhosis.[6] Stroke volume and contractile indices are typically normal or even increased at rest.

Financial or Other, Competing Interest: None.

Submission 22-10-2016, Peer Review 15-11-2016,

Acceptance 21-11-2016, Published 28-11-2016.

Corresponding Author:

Dr. Boddu Jyotirmayi,

Assistant Professor,

Department of General Medicine,

Andhra Medical College,

Visakhapatnam - 530002,

Andhra Pradesh.

E-mail: drboddudgo2001@yahoo.com

DOI: $10.14260 /$ jemds $/ 2016 / 1587$

\section{(c) $(1) \subseteq$}

However, under stressful stimuli such as exercise, haemorrhage or drug infusions, cirrhotic patients may show an attenuated systolic function compared to healthy controls.[7,8,9,10] The prevalence and extent of systolic dysfunction in cirrhotic patients appear to be variable.

In contrast, some element of diastolic dysfunction appears to be more common. Indeed, some authorities contend that some degree of diastolic dysfunction is present in virtually every patient with cirrhosis. $[9,10]$

\section{Aim of the Study}

The aim of the study is to assess the changes in cardiac echocardiography in patients with cirrhosis of liver.

\section{MATERIALS AND METHODS}

We have included 50 patients of cirrhosis of liver, who were ambulatory and haemodynamically stable as the study group. Another 50 persons were taken as the control group. The two groups were age and gender matched. The control group did not have any clinical features or risk factors for cardiovascular and liver disease. This was an observational study conducted in the Department of General Medicine, King George Hospital, Visakhapatnam, Andhra Pradesh.

All the participants were subjected to M-mode and twodimensional (2D) echocardiography with Doppler analysis. In this study the following parameters were considered: cardiac output (COP), end-diastolic (LVDD) and end-systolic (LVSD) left ventricular diameters; end-diastolic (RVDD) and endsystolic (RVSD) right ventricular diameters, interventricular- 
septal wall thickness (SWT), posterior left ventricular wall (PWT) thickness and left atrial diameter (LA). The systolic function was assessed by the ejection fraction of the left ventricle (EF) in percentage. Diastolic function was evaluated by $\mathrm{E} / \mathrm{A}$ ratio $(\mathrm{E}$ velocity = early maximal ventricular filling velocity, $\mathrm{A}$ velocity = late diastolic or atrial velocity) by analysis of transmitral flow.

All data are expressed as means and standard deviation. Difference variables are assessed by using the parametric tests; continuous variables are assessed by using T test.

\section{Exclusion Criteria}

Patients with the following conditions were excluded from the study - diabetes, hypertension, known cases of cardiac or pulmonary disease, anaemia, dyslipidaemia, gastrointestinal bleeding within the previous 3 months, those on beta blocker medication within the previous 3 weeks, intercurrent illness and critically ill patients.

\section{RESULTS}

Age and Gender

\begin{tabular}{|c|c|c|}
\hline & Cases & Controls \\
\hline Age (Mean) & 45 & 44 \\
\hline Males & 35 & 32 \\
\hline Females & 15 & 18 \\
\hline \multicolumn{3}{|c|}{ Table 1 } \\
\hline
\end{tabular}

The mean age of the patients and controls were comparable, i.e. 45 years and 44 years respectively.

\section{Prevalence of Ascites}

\begin{tabular}{|c|c|c|}
\hline & Cases & Controls \\
\hline Ascites present & 27 & NA \\
\hline Ascites absent & 23 & NA \\
\hline \multicolumn{3}{|c|}{ Table 2 } \\
\hline
\end{tabular}

54 percent of cases had ascites.

\section{Aetiology of Liver Cirrhosis}

\begin{tabular}{|c|c|}
\hline Aetiology & No. of Cases \\
\hline Alcohol & 18 \\
\hline HBV & 6 \\
\hline HCV & 7 \\
\hline Autoimmune & 2 \\
\hline Unknown & 16 \\
\hline \multicolumn{2}{|c|}{ Table 3 } \\
\hline
\end{tabular}

A vast majority of cases of cirrhosis were related to alcohol intake (36\%). Aetiology was not known in 32\% of cases. Twelve percent cases were related to HBV infection. HCV was the cause in $14 \%$ and autoimmune hepatitis in $2 \%$.

\section{Echocardiography Parameters of Cases and Controls}

\begin{tabular}{|c|c|c|c|}
\hline & $\begin{array}{c}\text { Cases } \\
\text { (Mean + SD) }\end{array}$ & $\begin{array}{c}\text { Controls } \\
\text { (Mean + SD) }\end{array}$ & P value \\
\hline AO $(\mathrm{cm})$ & $2.7+0.339$ & $2.9+0.363$ & 0.017 \\
\hline LA $(\mathrm{cm})$ & $3.5+0.575$ & $3.3+0.446$ & 0.006 \\
\hline IVSD $(\mathrm{cm})$ & $0.87+0.17$ & $0.9+0.172$ & 0.431 \\
\hline LVPWD (cm) & $0.86+0.17$ & $0.88+0.204$ & 0.648 \\
\hline EF (\%) & $65.64+8.11$ & $63.46+3.882$ & 0.089 \\
\hline COP (L/min) & $7.67+0.843$ & $5.10+0.342$ & 0.000 \\
\hline LVEDD $(\mathrm{cm})$ & $4.45+0.884$ & $4.26+0.538$ & 0.188 \\
\hline
\end{tabular}

\begin{tabular}{|c|c|c|c|}
\hline LVESD $(\mathrm{cm})$ & $2.84+0.647$ & $2.85+0.532$ & 0.88 \\
\hline RVEDD $(\mathrm{cm})$ & $2.89 \pm 0.29$ & $2.13 \pm 0.13$ & 0.000 \\
\hline RVESD $(\mathrm{cm})$ & $2.14 \pm 0.21$ & $1.8 \pm 0.13$ & 0.000 \\
\hline E/A & $1.07+0.309$ & $1.283+0.201$ & 0.000 \\
\hline \multicolumn{4}{|c|}{ Table 4 } \\
\hline
\end{tabular}

Table (4) shows the echocardiographic parameters in cirrhotic patients versus controls. No significant difference was noticed regarding the mean values of aorta diameter $\mathrm{AO}$ $(\mathrm{p}=0.017)$, left ventricular end diastolic diameter (LVEDD) ( $p$ $=0.188$ ), left ventricular end-systolic diameter (LVESD) ( $\mathrm{p}=$ $0.88)$ or ejection fraction (EF\%) $(p=0.089)$. The mean right ventricular end diastolic (RVEDD) and end systolic (RVESD) diameters were significantly higher in cirrhotic patients compared to healthy controls ( $p=0.000$ and 0.000 , respectively). Interventricular septal diameter (IVSD) and left ventricular posterior wall dimension (LVPWD) were also similar in patients and controls $(0.87 \pm 0.17$ vs $0.9 \pm 0.172 \mathrm{~cm}$ and $0.86 \pm 0.17$ vs $0.88 \pm 0.204 \mathrm{~cm}$, respectively). The mean E/A was significantly lower in cirrhotic patients $(1.07 \pm 0.309)$ compared to controls $(1.283 \pm 0.201)$. Left atrial diameter was slightly significantly larger in cirrhotic compared to controls $(\mathrm{p}=0.006)$.

Echocardiography Parameters of Cirrhotics with Ascites and without Ascites

\begin{tabular}{|c|c|c|c|}
\hline & $\begin{array}{c}\text { Cirrhosis with } \\
\text { Ascites } \\
\text { (Mean + SD) }\end{array}$ & $\begin{array}{c}\text { Cirrhosis } \\
\text { without Ascites } \\
\text { (Mean + SD) }\end{array}$ & $\begin{array}{c}\text { P } \\
\text { value }\end{array}$ \\
\hline EF (\%) & $66.07 \pm 9.71$ & $65.13 \pm 5.87$ & 0.69 \\
\hline $\begin{array}{c}\text { COP } \\
\text { L/min) }\end{array}$ & $7.38 \pm 0.61$ & $8.02 \pm 0.95$ & 0.01 \\
\hline $\begin{array}{c}\text { RVEDD } \\
\text { (cm) }\end{array}$ & $3.03 \pm 0.21$ & $2.71 \pm 0.29$ & 0.00 \\
\hline $\begin{array}{c}\text { RVESD } \\
(\mathrm{cm})\end{array}$ & $2.22 \pm 0.15$ & $2.06 \pm 0.23$ & 0.01 \\
\hline E/A & $0.83 \pm 0.09$ & $1.34 \pm 0.24$ & 0.00 \\
\hline \multicolumn{4}{|c|}{ Table 5 } \\
\hline
\end{tabular}

The ejection fractions were comparable in cirrhotics with ascites and without ascites. RVESD was slightly significantly larger in cirrhotics with ascites compared to those without ascites $(\mathrm{p}=0.01)$. However, RVEDD was significantly larger in cirrhotics with ascites than those without ascites $(p=0.00)$. The E/A was significantly lower in cirrhotics with ascites compared to those without ascites $(p=0.00)$.

Echocardiography Parameters of Alcoholic and NonAlcoholic Cirrhotics

\begin{tabular}{|c|c|c|c|}
\hline & $\begin{array}{c}\text { Alcoholics } \\
\text { (Mean + SD) }\end{array}$ & $\begin{array}{c}\text { Non-Alcoholics } \\
\text { (Mean + SD) }\end{array}$ & P value \\
\hline EF (\%) & $63.56 \pm 10.05$ & $66.81 \pm 6.67$ & 0.18 \\
\hline COP (L/min) & $7.43 \pm 0.83$ & $7.81 \pm 0.84$ & 0.14 \\
\hline RVEDD (cm) & $2.84 \pm 0.27$ & $2.91 \pm 0.31$ & 0.45 \\
\hline RVESD (cm) & $2.11 \pm 0.17$ & $2.10 \pm 0.22$ & 0.07 \\
\hline E/A & $1.02 \pm 0.23$ & $1.09 \pm 0.35$ & 0.44 \\
\hline \multicolumn{4}{|c|}{ Table 6 } \\
\hline
\end{tabular}

The ejection fraction and cardiac output were comparable between the alcoholics and non-alcoholics. Similarly, the right ventricular end diastolic diameter and end systolic diameter and $\mathrm{E} / \mathrm{A}$ ratio were not statistically different between the two groups. 


\section{DISCUSSION}

In the present study, the mean age and gender were comparable between the patients and the control group. Alcohol was the most common aetiological agent followed by viral infections with hepatitis B and C. No causative factor was found in $36 \%$ patients.

In the present study, we have demonstrated the structural and functional changes of the heart in the patients of cirrhosis of liver. The mean values of E/A ratio showed a statistically significant difference between cases and controls $(p=0.000)$, patients with ascites in particular, had significantly low mean ratio $(p=0.00)$ which is consistent with diastolic dysfunction. Therefore, ascites due to chronic liver disease probably plays a role in this setting. As the increased circulating blood volume leads to a high cardiac preload and decreased peripheral vascular resistance, i.e. low cardiac afterload, the alteration in the diastolic function is likely due to an impaired ventricular relaxation. Diastolic dysfunction could also be secondary to the stiffness of the ventricular wall as a result of cardiac hypertrophy described in cirrhotic cardiomyopathy. $(9,11)$

This study did not show statistically significant difference in the left ventricular posterior wall thickness and interventricular septal thickness among cases and controls ( $\mathrm{p}$ $=0.648$ and $\mathrm{p}=0.431$, respectively). Therefore, diastolic dysfunction could be due to the presence of ascites and/or to impaired liver function.

In this study, the right ventricular dimensions were significantly increased in cirrhotics with and without ascites $(p=0.000)$, probably as a consequence of an increased preload due to increased venous return in cirrhotic patients.(10)

In this study, there was no statistically significant difference in the left ventricular chamber dimensions between patients and controls ( $p=0.188, p=0.88)$. This is concordant with some previous observations of Valeriano et al,(10) but discordant with certain other observations of Laffi et al.(12)

In this study, we also investigated for the differences in the echocardiographic parameters in patients with cirrhosis due to alcohol and other aetiologies. We did not find any statistically significant difference between the two groups. This clearly points to the fact that cardiomyopathy in cirrhosis is not related to alcohol. Moreover, cirrhotics in this series had features of diastolic dysfunction. In contrast, alcoholic cardiomyopathy is characterised by systolic dysfunction. In this study, ejection fraction which is a marker of systolic function was in fact higher in cirrhotics compared to controls. Thus, cardiac changes even in patients with alcoholic cirrhosis can be attributed to cirrhosis itself rather than to alcohol consumption. This is in concordance with another Indian study by Jacob et al.(13) Alcohol does not appear to be a contributory factor to the development of cirrhotic cardiomyopathy, as only some of the patients with cardiac dysfunction had alcohol as the aetiology of their cirrhosis.

As the selection criteria for cirrhotics in our study excluded those with haemodynamically unstable advanced hepatic dysfunction, the present data essentially represents only limited spectrum of hepatic dysfunction. Clear trends of correlation may not come to light unless the entire spectrum of disease is studied.

Further studies dedicated to this purpose would accurately delineate the extent of correlation between severity of hepatic dysfunction and cardiac changes in cirrhotics. Such studies should include cirrhotics belonging to the entire spectrum of liver dysfunction.

\section{CONCLUSION}

Cirrhotic patients in our study showed right ventricular enlargement, normal left ventricular dimensions and normal systolic function at rest and diastolic dysfunction. However, patients with ascites were more likely to have diastolic dysfunction.

The echo parameters did not differ among alcoholic and non-alcoholic cirrhosis suggesting alcohol to be unlikely cause of cirrhotic cardiomyopathy.

Cardiac evaluation must be a pre-requisite in patients with cirrhosis undergoing stressful procedures like surgery, because the presence of cardiac involvement may add to the morbidity and mortality.

\section{REFERENCES}

1. Bosch J, Pizcueta P, Feu F, et al. Pathophysiology of portal hypertension. Gastroenterol Clin North Am 1992;21(1):114.

2. Ma Z, Lee SS. Cirrhotic cardiomyopathy: getting to the heart of the matter. Hepatology 1996;24(2):451-9.

3. Moller S, Henriksen JH. Cirrhotic cardiomyopathy: a pathophysiological review of circulatory dysfunction in liver disease. Heart 2002;87(1):9-15.

4. Zambruni A, Trevisani F, Caraceni P, et al. Cardiac electrophysiological abnormalities in patients with cirrhosis. J Hepatol 2006;44(5):994-1002.

5. Møller S, Henriksen JH. Cardiovascular complications of cirrhosis. Gut 2008;57(2):268-78.

6. Liu H, Song D, Lee SS. Cirrhotic cardiomyopathy. Gastroenterol Clin Biol 2002;26(10):842-7.

7. Lee SS. Cardiac abnormalities in liver cirrhosis. West J Med 1989;151(5):530-5.

8. Kelbaek H, Eriksen J, Brynjolf I, et al. Cardiac performance in patients with asymptomatic alcoholic cirrhosis of the liver. Am J Cardiol 1984;54(7):852-6.

9. Pozzi M, Carugo S, Boari G, et al. Evidence of functional and structural cardiac abnormalities in cirrhotic patients with and without ascites. Hepatology 1997;26(5):1131-7.

10. Valeriano V, Funaro S, Lionetti R, et al. Modification of cardiac function in cirrhotic patients with and without ascites. Am J Gastroenterol 2000;95(11):3200-5.

11. Wong F, Girgrah N, Graba J, et al. The cardiac response to exercise in cirrhosis. Gut 2001;49(2):268-75.

12. Laffi G, Barletta G, La Villa G, et al. Altered cardiovascular responsiveness to active tilting in nonalcoholic cirrhosis. Gastroenterology 1997;113(3):891-8.

13. Alexander J, Mishra P, Desai N, et al. Cirrhotic cardiomyopathy: Indian scenario. J Gastroenterol Hepatol 2007;22(3):395-9. 